\title{
The seismogenic process of the 2016 Meinong earthquake, southwest Taiwan
}

\author{
Strong Wen ${ }^{1, *}$, Yu-Lien Yeh $^{1}$, Yi-Zen Chang ${ }^{2}$, and Chieh-Hung Chen ${ }^{3}$ \\ ${ }^{1}$ Department of Earth and Environmental Sciences, National Chung Cheng University, Chiayi County, Taiwan \\ ${ }^{2}$ National Center for Research on Earthquake Engineering, Taipei City, Taiwan \\ ${ }^{3}$ Institute of Geophysics and Geomatics, China University of Geosciences, Hubei, China
}



Citation:

Wen, S., Y.-L. Yeh, Y.-Z. Chang, and C.-H. Chen, 2017: The seismogenic process of the 2016 Meinong earthquake, southwest Taiwan. Terr. Atmos. Ocean. Sci., 28, 651-662, doi: 10.3319/TAO.2017.02.17.01

\begin{abstract}
Southwest (SW) Taiwan lies on the deformation front of a plate collision zone. Most earthquakes in this region occur due to deformation of the upper crust, therefore, potential seismic hazards in this area must be considered. On 6 February 2016, a moderate, but disastrous earthquake $\left(\mathrm{M}_{\mathrm{L}}=6.6\right.$; depth $\left.=14.6 \mathrm{~km}\right)$ occurred in Meinong, a district in the Kaohsiung area of Taiwan. This earthquake produced three cluster-like aftershocks. Among them, two of the aftershocks clusters were not spatially correlated with the main earthquake. Additionally, the trends of these two seismic clusters were not associated with previously known faults or geological structures. Therefore, our major intention is not only to investigate the rupture process of the 2016 Meinong earthquake, but more importantly, to look into the corresponding seismogenic process. In this research, high quality strong-motion data was used to invert the slip distribution on the fault plane using the isochron method. In addition, we relocated aftershocks to further obtain focal mechanisms using a 3D velocity model. Coulomb failure stress maps are calculated for different depth ranges based on the obtained source slip distribution to verify whether the main-shock triggers nearby unknown faults or not. In conclusion, we suggest that there might exist a NWSE trending, north-dipping fault, which is located north of the source area and may have been triggered by the initial shock. We also conclude that the 2016 Meinong earthquake did trigger the pre-existing normal faults beneath Tainan City.
\end{abstract}

\section{INTRODUCTION}

Taiwan is a classic example of an area of seismic activity owing to vigorous plate collisions. The deformation front as proposed by the "thin-skinned" model (Suppe 1981) is composed of several active fold-and-thrust systems. An example of this model is the Chelungpu fault that caused the great 1999 Chi-Chi $\left(\mathrm{M}_{\mathrm{L}}=7.3\right)$ earthquake. To understand the seismogenic and earthquake nucleation processes in a fault zone is still a great challenge. Further, the interactions among different fault systems remain unsolved. In southwest (SW) Taiwan, most fault activity typically occurs in the upper crust within $10-15 \mathrm{~km}$ in depth (Lacombe and Mouthereau 2002; Lin et al. 2009). In addition, the occurrence of segmentation along a fault is also a common observation in Taiwan, which is caused by several stages of complex geological evolution. The heterogeneity of a fault

\footnotetext{
* Corresponding author

E-mail: strong@eq.ccu.edu.tw
}

makes it more difficult to understand the whole spectrum of the seismogenic process, as well as to answer the question of whether one strong earthquake can or cannot trigger neighboring faults to generate additional shocks. Despite the above challenges, it has been found that a strong main-shock is often accompanied by a series of aftershocks, which generally have the same focal mechanism as the main-shock; however, there is an exception. If the main-shock occurs in a highly fractured crust with complex fault systems that may not be recognized or know before (Nur et al. 1986; Wen et al. 2008), such as in Taiwan region, it could lead to the generation of different focal mechanisms among the main-shock and aftershocks (Chen et al. 2003; Wen et al. 2008). The explanation for this is that when main-shock strikes, it also triggers nearby faults and can produce a different slip type of earthquake sequence. Therefore, if the source region is located in a highly fractured zone with a web-like fault system in complex geological formations, its rupture behavior 
will be relatively complicated. In other words, answering the question of whether distinct focal mechanisms exist between main-shock and aftershock sequences may provide evidence and a linkage between earthquake triggering and interactions among faults (Steacy et al. 2005).

On 4 March 2010, a moderate earthquake occurred in the Jiasian area $\left(\mathrm{M}_{\mathrm{L}}=6.4\right.$, depth $\left.=22 \mathrm{~km}\right)$ in $\mathrm{SW}$ Taiwan (hereafter called the Jiasian EQ) (Ching et al. 2011; Huang et al. 2011; Wen et al. 2012; Lee et al. 2013). About two years later, another earthquake with $\mathrm{M}_{\mathrm{L}}=6.35$ (depth $=26 \mathrm{~km}$; hereafter called the Wutai EQ) occurred in the Wutai area, which is about $30 \mathrm{~km}$ away from the epicenter of the Jiasian EQ, and triggered a series of aftershocks (Chan and $\mathrm{Wu}$ 2012; Chiang et al. 2016). In Fig. 1, the blue and red circles indicate the aftershocks of the Jiasian EQ and the Wutai EQ, respectively. Six years later, on 6 February 2016, another disastrous earthquake $\left(\mathrm{M}_{\mathrm{L}}=6.6\right.$; depth $\left.=14.6 \mathrm{~km}\right)$ occurred in Meinong, Kaoshiung City, Taiwan (hereafter called the Meinong EQ). Figure 1 shows the epicenters of the three moderate earthquakes (denoted by red stars). The diameters of the solid circles are scaled by magnitude and represent the aftershocks of the 2016 Meinong EQ. The focal depth of each event is indicated by the gray scale. It can be observed that the spatial distribution of aftershocks has no relation to current known geological structures. Thus, to clarify the spatial relationship between the 2016 Meinong EQ and its aftershocks is the main intention of this research. In order to achieve this goal, we have conducted waveform inversion to investigate the slip distribution on the fault plane (AA' in Fig. 1), which will help us to comprehend the seismogenic process of the 2016 Meinong EQ and its spatial connection with the associated aftershocks.

In recent years, seismologists and earthquake engineers have extensively investigated the earthquake source process using strong ground motion records. Aki (1968) first applied a heterogeneous boundary elastic model to simulate the strong ground motion of the 1966 Parkfield earthquake. Following that study, several inversion approaches were developed to deal with complex configurations of slip distribution on a fault plane (Trifunac 1974; Olson and Apsel 1982; Hartzell and Heaton 1983; Takeo 1987; Beroza and Spudich 1988; Wald et al. 1991). In addition, Papageorgiou and Aki (1983a, b) used high-frequency seismic acceleration data to build a stochastic model to explain the source rupture process. In this study, the isochron synthesis method and repeated stochastic seismic inversion (Bernard and Madariaga 1984; Spudich and Frazer 1984; Zeng et al. 1993) are adopted to calculate slip distributions for each sub-fault block. Zeng et al. (1993) applied the above methods successfully to describe the rupture process of the 1989 Loma Prieta

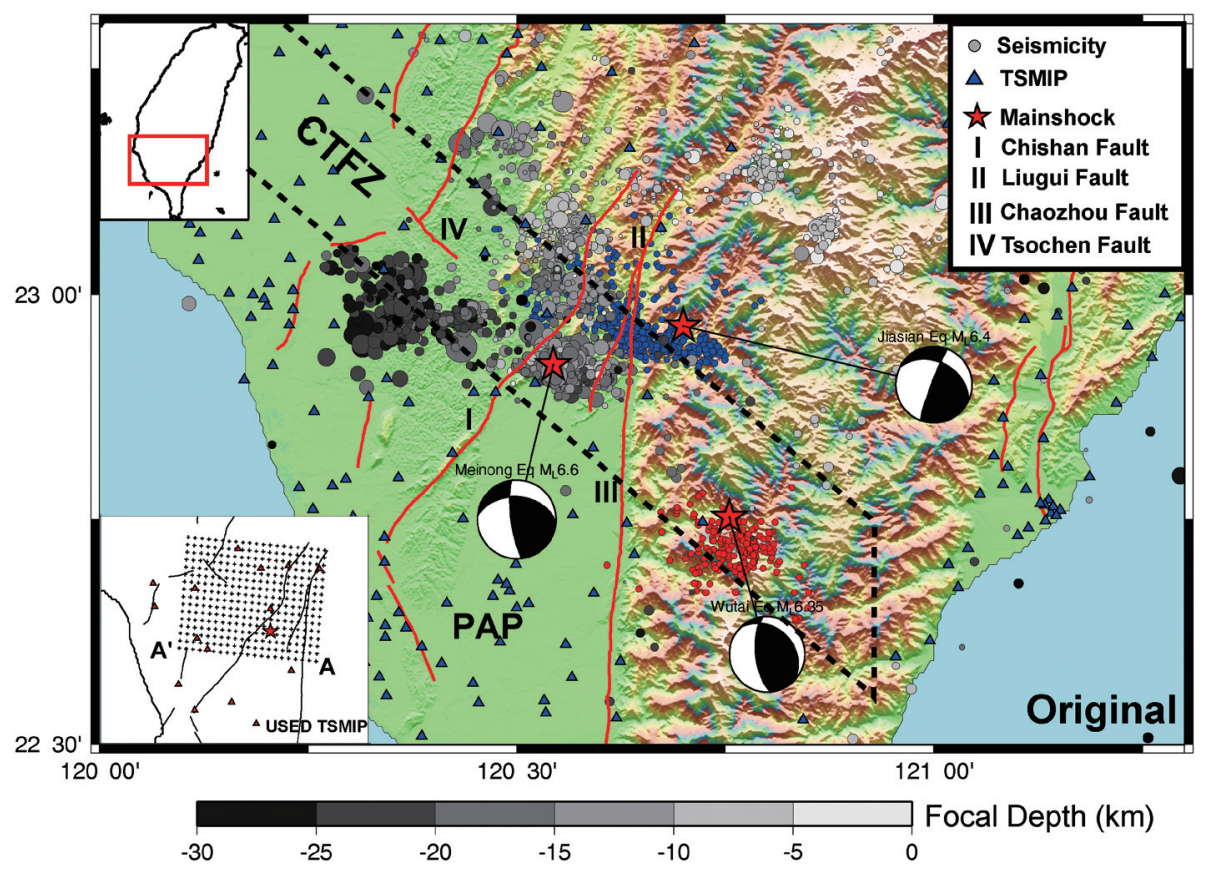

Fig. 1. Geological setting and topography map of study area. The solid blue triangles represent the locations of the CWBSN stations. The solid red stars indicate the epicenters of three moderate earthquakes that occurred in the study region from 2010 to 2016. The aftershocks of the 2016 Meinong EQ are denoted by solid circles scaled by magnitude. Gray scaling is used within the circles to indicate the depth of each event. Blue circles are the aftersshocks of the 2010 Jiasian EQ, while red circles are the aftershocks of the 2012 Wutai EQ. The red solid lines indicate active faults, while the black solid lines are the strike of the rupture plane (AA' shown in the inset located in the lower left-hand corner and the red triangular is indicated as the used station). The area enclosed by a black dashed rectangle indicates the CTFZ. The inset in the lower left-hand corner shows the grid points used in estimating slip distribution. The 't' sign presents the nodes of the rupture image. CSF: the Chishan fault; CZF: the Chaozhou fault; LGF: the Liugui fault; TCF: the Tsochen fault. (Color online only) 
earthquake. The high quality strong motion data recorded by the Taiwan Strong Motion Instrumentation Program (TSMIP), operated by the Central Weather Bureau, Taiwan, gives us an opportunity to examine the rupture process of the 2016 Meinong EQ as well as its interactions with nearby fault systems (see Table 1).

\section{GEOLOGICAL SETTING}

The geological structures in our geographical area of study consist mainly of two oblique thrust-type faults, the Chaozhou Fault (CZF) and the Chishan fault (CSF). The CSF, which trends in the NE-SW direction, is a prominent boundary between the Western Foothills (WF) and the Pingdong alluvial plain (PAP) (Fig. 1). Lin et al. (2000) shows that the CSF is a thrust fault with left-lateral slip motion from the evidence of slickenside. The dip in the CSF was estimated to be $65^{\circ}$ from gravity interpretation (Hsieh 1970). The west of the CSF is covered with relatively un-deformed mudstone from the Pliocene and Pleistocene epochs, and the east of the CSF is covered with late Miocene sandstone (Chiang et al. 2004). In contrast, there exists a fold-and-thrust fault system in the east region of the CZF, which results in ongoing mountain building. From previous surveys, the CZF is a high angle left-lateral strike-slip fault (Tsan and Keng 1968) that acts as a boundary between the PAP and the Central Mountain Range (CMR). Several studies have determined that the dip in the CZF is estimated to be about $70-80^{\circ}$ based on some geophysical data, such as micro-earthquake and gravity data (Yu et al. 1983). The eastern region of the CZF is composed of metamorphic rock, e.g., slate, phyllite, and metamorphic sandstone. In addition to the two main fault systems, the Liugui fault (LGF) is also a strike slip fault with a NNE-SSW strike direction and left-lateral slip motion. The dip in the LGF is approximately vertical, and fault breccia and gouge are present at the surface (Tsan and Keng 1968). According to earlier studies (Rau and Wu 1998; Lacombe et al. 2001), our study area is located within a seismic zone called the Chishan Transfer Fault Zone (CTFZ; enclosed by a dashed rectangle, Fig. 1), which trends in the NW-SE direction with a left-lateral strike slip sense (Ching et al. 2011). From the spatial distribution of aftershocks of the three moderate earthquakes, the general trends are more or less parallel to the CTFZ, but not associated with the previously known faults, such as the CZF and CSF. Otherwise, the Tsochen fault (TCF) which trends in the NW-SE direction may has a very high probability to be the surface expression of the CTFZ (Huang et al. 2004). Although the fault length is about $10 \mathrm{~km}$ to the TCF, but the geological significance is very important that this fault separates the north and south sides of the geological structures in the southwest foothills of Taiwan. Of great interest is the spatial distribution of aftershocks followed by the 2016 Meinong EQ. That is, one sequence is located to the west of the epicenter with most events occurring at depths greater than $20 \mathrm{~km}$ (denoted by Zone 2, Fig. 2a), while another sequence is located to the north of the epicenter with focal depths between 5 and $15 \mathrm{~km}$ (denoted by Zone 3, Fig. 3a). Additionally, one sequence called Zone 1 (Fig. 3a) surrounds the epicenter of the main-shock, the depth range of events in this zone is between 10 and $20 \mathrm{~km}$.

\section{DATA PROCESSING AND METHODOLOGY}

In this section, we will describe the core features of the data set and the approaches for investigating the seismogenic process of the 2016 Meinong EQ sequence. We have divided our work into three phases. Phase (I) began with relocating the earthquake sequence with a 3D tomographic velocity model obtained by Wen et al. (2012). Due to the complex pattern of the distribution of aftershocks, we used only the first month of data to relocate the earthquake sequence and identify the rupture pattern. Next, we used the first P-wave polarities to determine focal mechanisms for events with clear polarities greater than 8 , and re-calculated the azimuths and take-off angles of the direct P-wave using the pseudo bending ray tracing technique (Thurber 1983). The polarities of the direct P-wave recorded by the CWBSN were used and we relocated the earthquake sequence through the $3 \mathrm{D}$ velocity model (Wen et al. 2012) and obtain the refresh information, which include the azimuths and take-off angles. Then we use the information to calculate the fault plane solutions by FPFIT software (Reasenberg and Oppenheimer 1985). Figure 2 shows the fault plane solutions of the main-shock as well as 22 aftershocks (also see Table 2). In Zone 2, most of the focal mechanisms of events that occurred at depths between 15 and

Table 1. The list of TSMIP stations that was used to the Meinong earthquake source waveform inversion.

\begin{tabular}{ccccc}
\hline Station & Longitude & Latitude & Elevation $(\mathbf{m})$ & Amplitude MAX. \\
\hline KAU068 & 120.5443 & 22.9759 & 125. & $2.00 \mathrm{G}$ \\
KAU028 & 120.5990 & 22.8261 & 95. & $2.00 \mathrm{G}$ \\
CHY061 & 120.5190 & 23.0747 & 90. & $2.00 \mathrm{G}$ \\
KAU012 & 120.3793 & 22.8779 & 20. & $2.00 \mathrm{G}$ \\
KAU047 & 120.5906 & 23.0804 & 278. & $2.00 \mathrm{G}$ \\
CHY065 & 120.3517 & 22.9042 & 36. & $2.00 \mathrm{G}$ \\
MTN155 & 120.6730 & 23.0734 & 417. & $2.00 \mathrm{G}$ \\
KAU021 & 120.4425 & 22.7499 & 55. & $2.00 \mathrm{G}$ \\
CHY063 & 120.3465 & 23.0259 & 30. & $2.00 \mathrm{G}$ \\
CHY062 & 120.4591 & 23.1217 & 40. & $2.00 \mathrm{G}$ \\
KAU026 & 120.5070 & 22.6978 & 42. & $2.00 \mathrm{G}$ \\
KAU086 & 120.3030 & 22.7927 & 33. & $2.00 \mathrm{G}$ \\
KAU066 & 120.3454 & 22.7302 & 31. & $2.00 \mathrm{G}$ \\
CHY096 & 120.2407 & 22.9814 & 39. & $2.00 \mathrm{G}$ \\
CHY078 & 120.2367 & 23.0380 & 8. & $2.00 \mathrm{G}$ \\
\hline
\end{tabular}






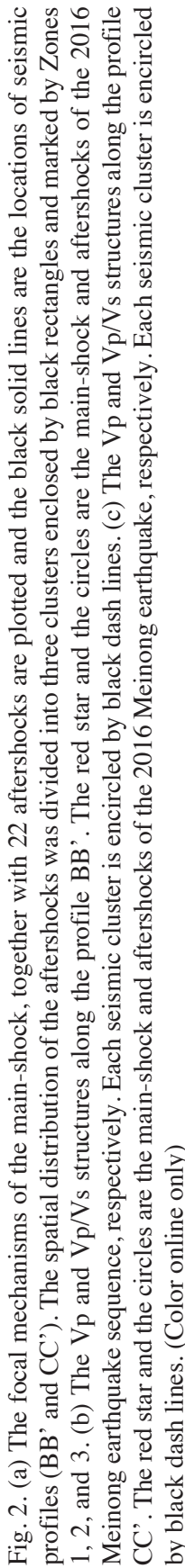




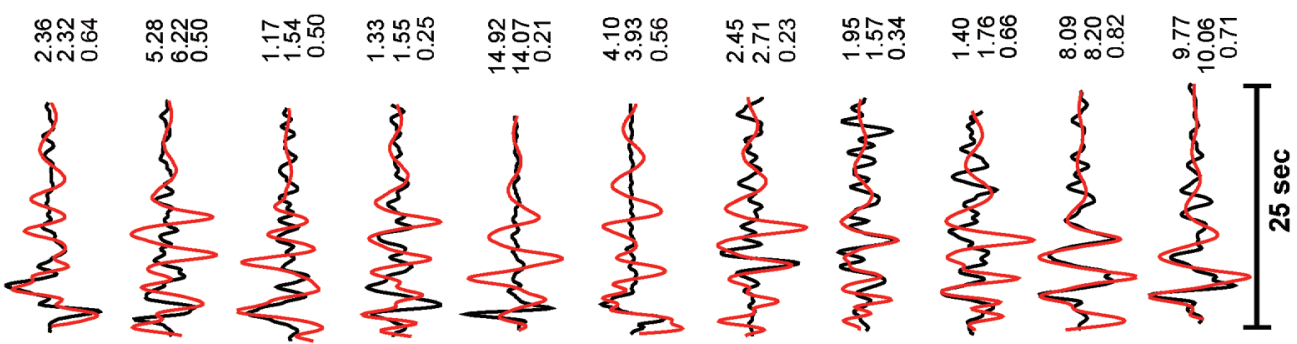

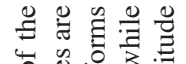

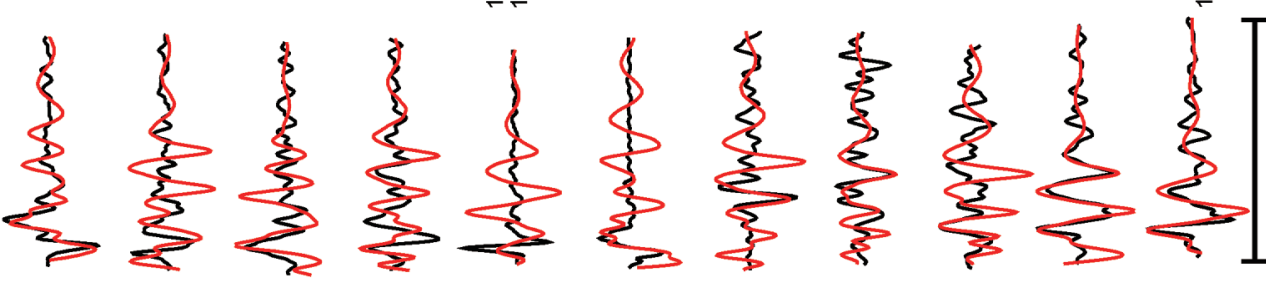

手焉

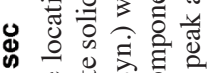
พิ

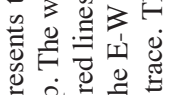
焉.

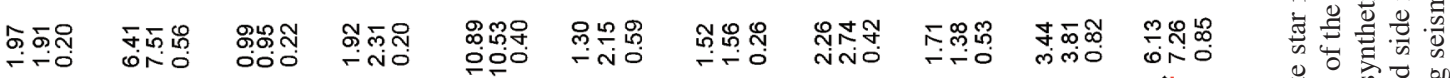

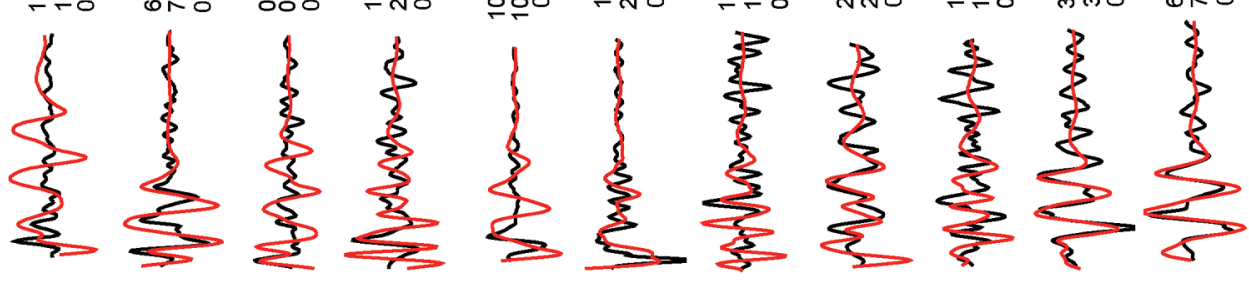







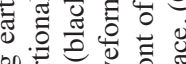

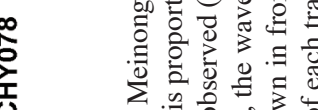

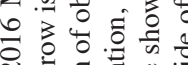

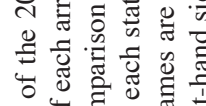

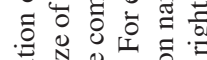



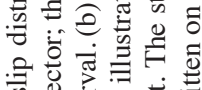
की on o 氖昰它范 o.

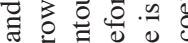
현



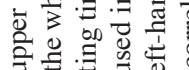
记

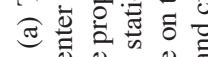



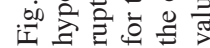


Table 2. The obtained fault plane solutions from the 2016 Meinong EQ's aftershocks.

\begin{tabular}{cccccccc}
\hline Date/hour/min:second & Lon. & Lat. & Dep $(\mathbf{k m})$ & Mag. & Strike & Dip. & Rake \\
\hline 20160205/20/18:43.09 & 120.3610 & 22.9600 & 28.0 & 3.51 & 170 & 75 & 160 \\
20160205/21/07:19.27 & 120.3490 & 23.0052 & 21.1 & 4.28 & 0 & 85 & -160 \\
20160205/22/14:26.57 & 120.3703 & 22.9905 & 21.7 & 3.08 & 355 & 90 & -160 \\
20160205/23/07:29.42 & 120.3355 & 22.9978 & 27.4 & 3.24 & 160 & 70 & 150 \\
20160206/00/17:33.49 & 120.4522 & 22.9202 & 11.2 & 2.19 & 260 & 10 & 150 \\
$20160206 / 13 / 41: 57.26$ & 120.3507 & 22.9598 & 21.4 & 3.49 & 265 & 70 & 20 \\
$20160207 / 12 / 14: 16.31$ & 120.3457 & 23.0110 & 27.2 & 2.03 & 70 & 15 & 60 \\
$20160208 / 09 / 54: 51.65$ & 120.5722 & 23.0060 & 11.1 & 3.76 & 75 & 90 & -90 \\
$20160208 / 09 / 54: 51.65$ & 120.5722 & 23.0060 & 11.1 & 3.76 & 75 & 90 & -90 \\
$20160208 / 13 / 16: 23.26$ & 120.5845 & 23.0737 & 8.4 & 1.22 & 50 & 75 & 160 \\
$20160209 / 19 / 56: 04.20$ & 120.3240 & 22.9977 & 27.4 & 2.93 & 0 & 80 & -160 \\
$20160210 / 00 / 40: 26.71$ & 120.4405 & 23.1347 & 17.8 & 3.79 & 345 & 25 & 110 \\
$20160210 / 06 / 37: 52.40$ & 120.5722 & 23.1092 & 2.8 & 3.14 & 85 & 50 & -100 \\
$20160210 / 10 / 32: 24.00$ & 120.4543 & 22.9752 & 19.2 & 2.04 & 75 & 55 & -30 \\
$20160210 / 13 / 34: 27.79$ & 120.5663 & 22.9035 & 14.6 & 3.84 & 0 & 70 & -110 \\
$20160211 / 08 / 52: 25.90$ & 120.5397 & 23.0532 & 14.2 & 1.66 & 15 & 15 & 30 \\
$20160212 / 01 / 10: 49.70$ & 120.5440 & 22.9325 & 10.7 & 3.82 & 140 & 5 & -50 \\
$20160212 / 20 / 56: 25.33$ & 120.4147 & 22.9758 & 21.8 & 2.58 & 5 & 80 & -170 \\
$20160217 / 04 / 15: 21.02$ & 120.5415 & 22.8990 & 18.8 & 3.58 & 70 & 65 & -150 \\
$20160218 / 20 / 41: 50.38$ & 120.5720 & 22.9832 & 13.4 & 2.77 & 260 & 85 & -20 \\
$20160218 / 21 / 20: 06.78$ & 120.2990 & 22.9682 & 29.4 & 4.25 & 40 & 65 & -90 \\
$20160226 / 20 / 39: 06.61$ & 120.4685 & 22.9963 & 21.9 & 1.37 & 305 & 85 & -130 \\
$20160310 / 03 / 41: 27.21$ & 120.3708 & 22.9653 & 28.4 & 3.43 & 175 & 85 & 160 \\
\hline & & & & & & &
\end{tabular}

$20 \mathrm{~km}$ show left-lateral strike-slip motion. It is worth noting that there were several normal faulting events that occurred at depths greater than $20 \mathrm{~km}$.

Another interesting feature after relocation is that the spatial distributions of aftershock sequences are cluster-like (Fig. 2a). Thus, the purpose of phase (II) of this study is to apply the method proposed by Robinson and Mcginty (2000) to invert the orientation of principal stress axes in each cluster. This method is very useful for cases where the source area is dominated by micro-earthquakes and focal mechanisms are unavailable or unable to be determined precisely due to the lack of clear P-wave arrivals (Wen et al. 2012). The aftershock sequences were divided into three groups as mentioned in section 2: Zones 1, 2, and 3. There are 391, 469, and 579 P-wave readings in Zones 1, 2, and 3 respectively, which are later used in performing stress inversion (see Fig. 2).

The tasks in phase (III) are described as follows. According to the CWB report, the focal mechanism of the 2016 Meinong EQ has a strike of $275^{\circ}$ with a dip of $42^{\circ}$, and the rake angle is $17^{\circ}$. For comparison, we used fault plane solutions obtained from the USGS and the BATs (moment tensor solution) to verify the possible range of fault orienta- tions. Thus, we used the three fault plane solutions above, with fault attitude varying $\pm 30^{\circ}$ at increments of $5^{\circ}$ to generate synthetic waveforms and find the minimum misfit solutions (Wen et al. 2008). The dimensions of the input fault model are 40 and $30 \mathrm{~km}$ along the strike and dip direction respectively (see AA' in Fig. 1); and the fault is buried at a depth between 15 and $45 \mathrm{~km}$ along the dip direction. The $1 \mathrm{D}$ velocity structure was modified from the results of Wen et al. (2012) to calculate Green's functions (see Table 3). Finally, we estimated the slip distribution on the fault plane. To gain better solution convergence, we selected 15 stations that are located near the source area of the 2016 Meinong EQ [see Fig. 1 (the red triangles) and Table 1] due to the onset of the maximum peak velocity often coincides with the arrival time of the direct S-waves for epicentral distances less than $30 \mathrm{~km}$ (Zeng et al. 1993). Therefore, we used the direct $\mathrm{S}$-waves displacement data and bandpass filtering from $0.2-0.8 \mathrm{~Hz}$ with a taper of 0.05 for waveform inversion and rupture time modeling (Zeng et al. 1993; Wen et al. 2008). Several studies (Beroza 1991; Wald et al. 1991; Cohee and Beroza 1994) suggest that slip distributions can have strong lateral variations, even with constant rupture velocity. In this research, we set the rupture velocity of 
Table 3 . The $1 \mathrm{D}$ velocity modified from Wen et al. (2012).

\begin{tabular}{ccc}
\hline Layer $(\mathbf{k m})$ & $\mathbf{V p}\left(\mathbf{k m ~ s}^{-1}\right)$ & $\mathbf{V s}\left(\mathbf{k m ~ s}^{-1}\right)$ \\
\hline 0.00000 & 2.10000 & 1.10000 \\
0.50000 & 3.97762 & 2.21683 \\
2.00000 & 5.46555 & 3.03349 \\
5.00000 & 5.80191 & 3.17667 \\
10.00000 & 6.16778 & 3.33857 \\
15.00000 & 6.53365 & 3.68603 \\
25.00000 & 7.07587 & 3.97571 \\
35.00000 & 7.87285 & 4.44921 \\
50.00000 & 8.02000 & 4.72905 \\
\hline
\end{tabular}

source time function to $2.5 \mathrm{~km} \mathrm{~s}^{-1}$ and the rise time to $0.8 \mathrm{~s}$, which are constraints from waveform fitting with minimum error. The input velocity model beneath the Meinong area is derived by Wen et al. (2012). For density estimation, we adopted the empirical formula $\rho=1.7+0.2 \alpha$, where $\alpha$ is the P-wave velocity.

\section{RESULTS AND DISCUSSIONS}

According to the original location of aftershocks, the 2016 Meinong EQ sequence is very complex and the distribution is different with the 2010 Jiasian EQ sequence and 2012 Wutai EQ sequence in the study area (see Fig. 1). Therefore, we present the distribution of the relocated aftershocks shows three distinct clusters when average RMS of travel-time residuals is reduced to $0.21 \mathrm{~s}$ in the 3 -D solution (Wen et al. 2012). The relocated aftershocks show some changes with respect to the location given by the CWB, but the results confirm that the distributions of aftershocks not only occurred around the source area, but also that some seismic events at varying depths occurred to the west and north of the source area (see Fig. 2a, Zones 1, 2, and 3, dotted circles). Therefore, in order to distinguish the distribution of aftershocks and main-shock, two profiles were selected to illustrate the depth-dependent characteristics of the three seismic clusters. The profile BB' is parallel to the strike of the CTFZ and cuts across Tainan City, whereas the profile $\mathrm{CC}^{\prime}$ is perpendicular to the profile $\mathrm{BB}^{\prime}$. Zone 1 encloses the main-shock, which is bordered by a clustered aftershock sequence (Fig. 2b). The aftershocks that occurred in Zone 2 show a narrow-band distribution with a dip to the west roughly observed from the profile BB' (Fig. 2b). Zone 3 exhibits seismic clusters primarily with depths less than 20 km (Fig. 2c).

\subsection{The Profile BB'}

In order to envision the geological structures and evo- lution of the study area, we choose the same two profiles to illustrate the 3D tomography model. In Fig. 2b, a prominent low $\mathrm{Vp}$ anomaly zone with high $\mathrm{Vp} / \mathrm{Vs}$ ratio is apparent to the west of the CSF which is derived from the 3-D velocity model (Wen et al. 2012). This zone extends to a depth of $30 \mathrm{~km}$ which suggests that thick accumulated sediments exist in the accretionary wedge (the blue color in Vp perturbation) (Leggett et al. 1979; Shyu et al. 2005), and that the fault type in this area is a normal or strike-slip mechanism (Lin et al. 2009). Therefore, we consider that the thick, low $\mathrm{Vp}$ anomaly may reflect the typical character of an accretionary wedge with unconsolidated sediments (Leggett et al. 1979). From other investigations, Wu et al. (2007) also found that there is a low $\mathrm{Vp}$ anomaly zone with high $\mathrm{Vp} /$ Vs ratio beneath Tainan City, which is in the east end of the profile BB'; Lacombe et al. (2001) point out that there exists a fluid-rich muddy formation in the uppermost crust beneath our study area.

\subsection{The Profile CC'}

In Fig. 2c, there is a high $\mathrm{Vp}$ with low $\mathrm{Vp} / \mathrm{Vs}$ ratio anomaly zone dipping southward as well as a sharp boundary between the high and low $\mathrm{Vp}$ anomaly zones in the northern part of the profile CC'. This result is consistent with the observation that the southern part of the CMR is composed mainly of granitic continental rocks (Wu et al. 2007). Otherwise, there is a high $\mathrm{Vp} / \mathrm{Vs}$ ratio anomaly zone with a low Vp anomaly in the southern part of this profile and it can be referred to the structures of PAP (Wen et al. 2012). Furthermore, we projected the focal mechanism of the Meinong earthquake sequence along the profile $\mathrm{BB}$ ' and $\mathrm{CC}^{\prime}$ and found that the potential fault plane is analogous with the trend of the seismic zone.

About the source inversion, we present our final results of the slip distribution of the 2016 Meinong EQ from a low frequency perspective. In Fig. 3a, we show the slip distribution on the fault plane (AA'). The epicenter is indicated by a black star; the rupture time contour is represented by black solid lines with a contour interval of $2.5 \mathrm{~s}$; and the white arrows show the direction of slip for each sub-fault, with size proportional to the magnitude of slip. We found two significant slip zones; the first is located $10 \mathrm{~km}$ north of the hypocenter at a greater depth. This area is dominated by strikeslip faulting with a maximum offset of approximately 2.7 $\mathrm{m}$. This zone can be considered as an asperity with an area of $20 \times 15 \mathrm{~km}^{2}$. To the north of the man-shock epicenter, another prominent slip area dominated by thrust type seismic events is observed. The total seismic moment is estimated to be $4.46 \times 10^{18} \mathrm{Nm}$, similar to the result derived from the USGS (http://earthquake.usgs.gov/earthquakes/eventpage/ us20004y6h\#moment-tensor). The comparison between the observed waveform and the synthetic waveform is shown at the bottom panel of Fig. 3a. The synthetic seismograms were 
plotted with red solid lines and at the same scale. The correlation between the synthetic and observed data is, in general, quite strong. The value listed at the right-hand side of each trace represents the corresponding peak value and crosscorrelation coefficient. However, at some stations, the correlation is poor such as KAU068, KAU047, MTN155, and KAU021 in the N-S component, and KAU028, KAU021, CHY063, and KAU026 in the E-W component (see Fig. 3b bottom and right panels, the cross-correlation coefficient is lower than 0.25). Beneath these stations, there exists $10 \mathrm{~km}$ of thick unconsolidated sediments that leads to strong site effects causing the waveform fitting to be relatively poor (Bard and Riepl-Thomas 2000; Lin and Watts 2002). The slip distribution depicted in Fig. 3a indicates that the failure process of the 2016 Meinong EQ might have initiated as a small event with the rupture accelerating and slip amplitude increasing toward the west where Tainan City is located, causing a major seismic hazard in the area.

In order to understand the stress field of these three seismic clusters, except to the 22 fault plane solutions that were obtained using the FPFIT technique (Reasenberg and Oppenheimer 1985), we adopted the stress inversion method (Robinson and Mcginty 2000) to retrieve the orientation of principal stress axes $\sigma_{1}$ and $\sigma_{3}$ in each zone. This method allows us to use the numerous smaller aftershocks rather than the more limited set of fault plane solutions from the earthquake sequence. The results are obtained by setting the 95\% confidence interval for $\sigma_{1}$ and $\sigma_{3}$ from 1000 resamples (Michael 1987). The beach balls diagrams in Fig. 4 show the focal mechanisms (lower hemisphere projection) corresponding to an optimal fault type in Zones 1, 2, and 3 . The preferred fault plane shows normal faulting in Zone 2, thrust faulting in Zone 3 and left-lateral with reverse faulting in Zone 1, which are all consistent with the fault plane solutions obtained from first $\mathrm{P}$ polarities. Our findings also suggest that the aftershocks of the 2016 Meinong EQ are not associated with any currently known geological structure in proximity to the source area. Based on our results, we can remark that the fault type in the upper crust of Zones 1 and 2 is similar with the CTFZ which exhibits left-lateral thrust rupture behavior (Rau and Wu 1998; Lacombe et al. 2001; Ching et al. 2011; Wen et al. 2012); however, the aftershocks that occurred in the lower crust in Zone 2 and those shallowdepth thrust events in Zone 3 were generated by triggering pre-existing structures or blind faults. Nevertheless, the interaction between the main-shock and the aftershocks is obviously very complicated, and the precise spatial-temporal process is an important mission in future works.

\section{TECTONIC IMPLICATIONS}

By combining results from investigating the slip distribution, focal mechanisms, velocity model, and the relocated 2016 Meinong earthquake sequence, we find that there may exist a blind fault with a NW-SE strike beneath Tainan City (Zone 2). Moreover, the orientations of the principal stress axes beneath our study area are similar to the concluding remarks made by Wen et al. (2012). They suggest that Zones 3 and 4 (Fig. 5) are in convergent zones caused by the arccontinental collision, and Zone 5 corresponds to the Jiasian EQ (Wen et al. 2012). Additionally, Zone 6 corresponds to the 2012 Wutai EQ which used 389 P-wave first motion polarity readings from the related aftershocks and also occurred in the transfer fault zone. Both Zones 5 and 6 exhibited thrust slip with the NW strike direction. Based on previous studies, the southern area of the CTFZ (e.g., PAP area in Fig. 1) exhibits tectonic escape which may relate to the Manila subduction zone and inactivity in this area (Lacombe et al. 2001; Wen et al. 2012). As the north of the CTFZ still exhibits thrust faulting, which implies ongoing collisions; the shortening effect still dominates (Bos et al. 2003). Hence, the different tectonic processes lead the potential blind fault to be active to cause the 2016 Meinong earthquake sequence. Therefore, we found that the rupture behavior in SW Taiwan not only exhibits thrust and strikeslip focal mechanisms (Rau and Wu 1998; Ching et al. 2011; Wen et al.2012), but also worth to note that the CTFZ would play an important role among the different tectonic processes and increase the seismic potential.

For the causal relationship between the aftershock clusters, we also calculated Coulomb failure stress based on the source slip distribution obtained in this study. The calculation can help us to clarify the question of whether the seismic events that occurred in Zones 1, 2, and 3 were triggered or not. Figure 6 shows Coulomb stress distributions at three different depth ranges. On the left panel, we also plotted the principal stress orientations in each zone. In Zone 2, at a depth range of 20 - $30 \mathrm{~km}$ where deeper aftershocks occurred (the western part of the sequence), the calculated Coulomb failure stress does seem to trigger the paleo-normal faults existing in the lower crust beneath the Tainan Basin (Lee et al. 1993; Lacombe and Mouthereau 2002; Sibuet et al. 2004). For the aftershocks in Zone 3, at the depth range of $0-10 \mathrm{~km}$, the map of Coulomb failure stress (Fig. 5) still indicates that those events were triggered. Even when we used a homogeneous half-space in the calculation of Coulomb failure stress, the results continued to demonstrate solid evidence that the failure process of the 2016 Meinong EQ could have triggered the nearby fault system.

\section{CONCLUSIONS}

Traditionally, a fault kinematic model is obtained using strong motion data to calculate slip distribution on the fault plane, often not taking into account the stress state on the fault plane. Aki (1984) pointed out that considering barriers and asperities on a fault plane is exceptionally important to estimating the strong ground motion as well as to 
(a) $+=\sigma_{1,0}=\sigma_{3}$
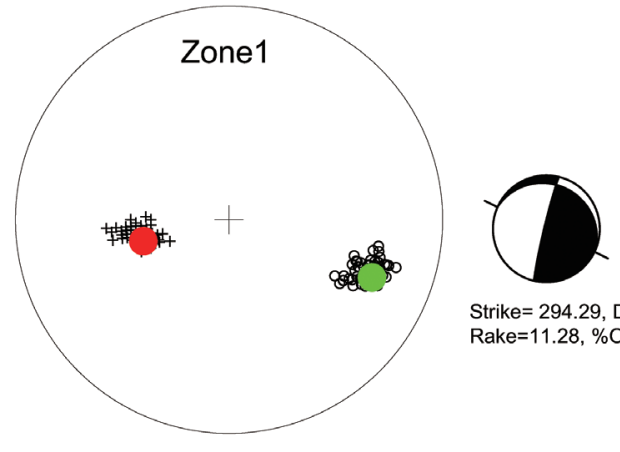

Strike $=294.29$, Dip $=17.11$ Rake $=11.28, \%$ OK $=82.1$

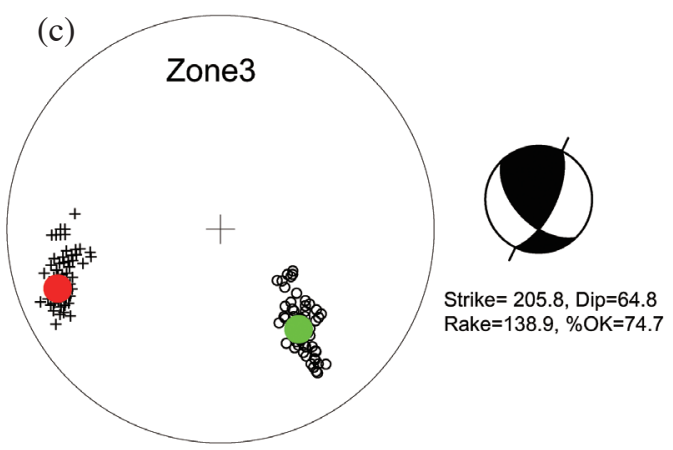

(b)

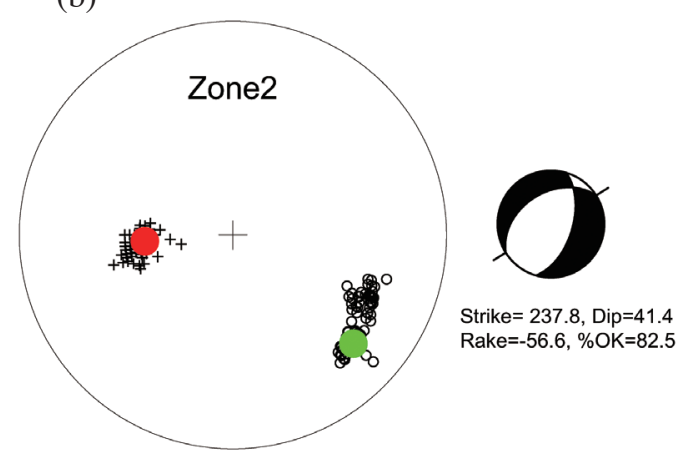

Fig. 4. The orientations of the $\sigma_{1}$ (denoted by '+') and $\sigma_{3}$ (denoted by the circle symbol) axes from stress inversion of 1000 resampled polarities for (a) Zone 1 (top panel), (b) Zone 2 (middle panel), and (c) Zone 3 (bottom panel). The results are based on 95\% confidence limits. The "beach balls" show the optimal focal mechanisms (lower hemisphere projection). (Color online only)

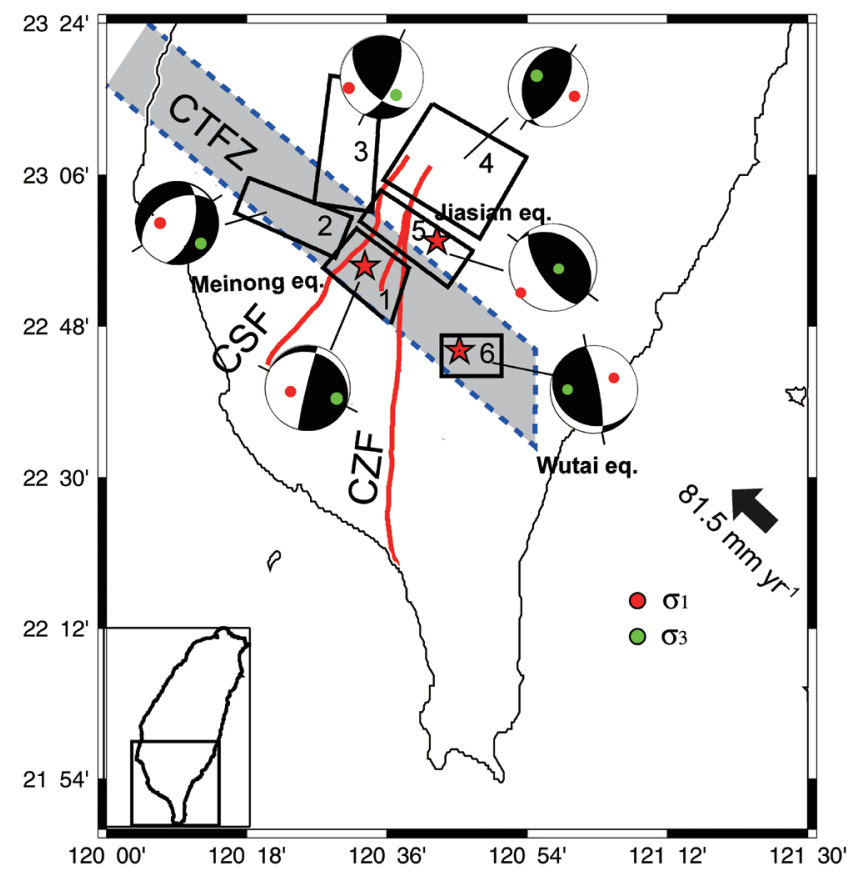

Fig. 5. The results of regional stress inversion for six zones within the CTFZ (Wen et al. 2012). The beach ball diagrams show the attitude of the stress tensors and the solid red and green circle indicates as $\sigma_{1}$ and $\sigma_{3}$ respectively. The convergence rate in Taiwan area is $81.5 \mathrm{~mm} \mathrm{yr}^{-1}\left(\mathrm{Yu}_{\mathrm{u}}\right.$ et al. 1997). The red solid stars show the epicenters of the 2010 Jiasian EQ, 2012 Wutai EQ, and 2016 Meinong EQ. The CTFZ is indicated by the gray area enclosed by the blue dashed rectangle. (Color online only) 
(a)

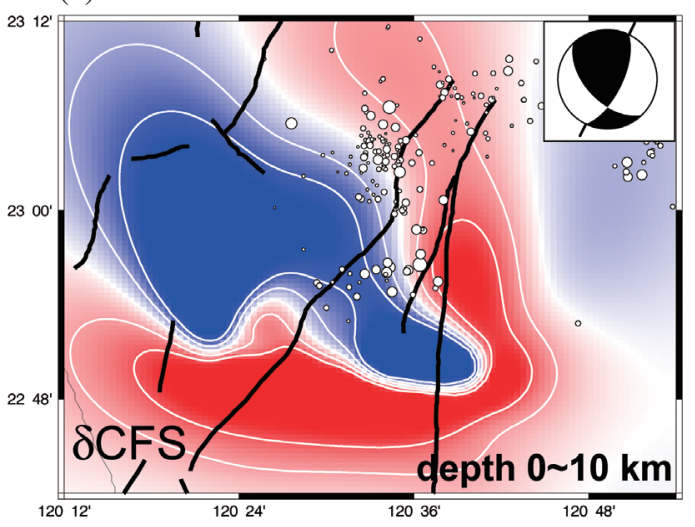

(c) (b)



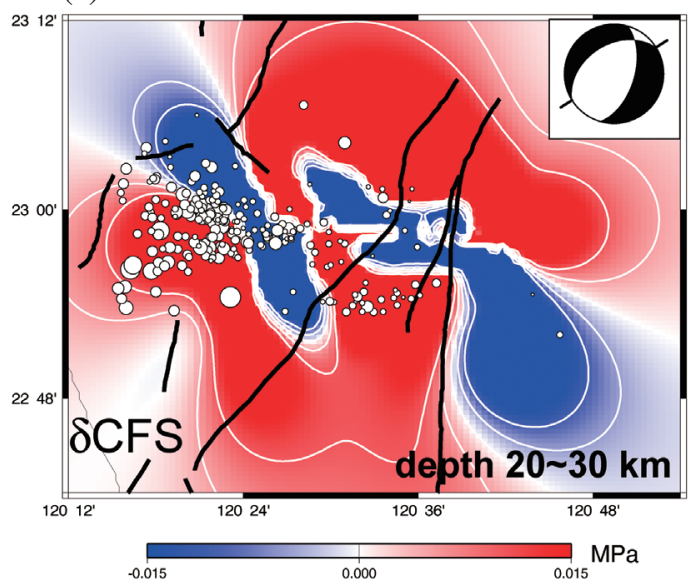

Fig. 6. The Coulomb failure stress map at different depth ranges. White solid circles indicate aftershocks of the 2016 Meinong EQ. (a) At depths between 0 and $10 \mathrm{~km}$, the optimal fault plane solution is plotted in the upper right-hand corner. The mechanism is a thrust-fault type. (b) At depths between 10 and $20 \mathrm{~km}$, the optimal fault plane solution is plotted in the upper right-hand corner. The mechanism demonstrates left-lateral slip motion. (c) At depths between 20 and $30 \mathrm{~km}$, the optimal fault plane solution is plotted in the upper right-hand corner. The mechanism is a normal-fault type. (Color online only)

understanding the seismogenic process of an earthquake.

From the velocity profiles, we can see that the CSF and the possible blind fault with NW-SE strike are both important boundaries between the accretionary wedge and the intervening continental sliver. Our results also suggest that the left-lateral thrust motion of the main-shock may be caused by pre-existing blind faults. Finally, we conclude that a blind, left-lateral reverse fault exists and imply that the main-shock affects the nearby fault system and triggers the occurrence of aftershocks with normal and strike-slip mechanisms.

Acknowledgements We would like to thank the Taiwan Central Weather Bureau for providing high quality seismic data. This research is supported by MOST-105-2116-M194-009-MY3 and MOST-105-2116- M-194-018.

\section{REFERENCES}

Aki,K., 1968: Seismic displacements near a fault.J.Geophys.
Res., 73, 5359-5376, doi: 10.1029/JB073i016p05359. [Link]

Aki, K., 1984: Asperities, barriers, characteristic earthquakes and strong motion prediction. J. Geophys. Res., 89, 5867-5872, doi: 10.1029/jb089ib07p05867. [Link]

Bard, P. Y. and J. Riepl-Thomas, 2000: Wave propagation in complex geological structures and their effects on strong ground motion. In: Kausel, E. and G. D. Manolis (Eds.), Wave Motion in Earthquake Engineering, WIT Press, Southampton, Boston, 37-95.

Bernard, P. and R. Madariaga, 1984: A new asymptotic method for the modeling of near-field accelerograms. Bull. Seismol. Soc. Am., 74, 539-557.

Beroza, G. C., 1991: Near-source modeling of the Loma Prieta earthquake: Evidence for heterogeneous slip and implications for earthquake hazard. Bull. Seismol. Soc. Am., 81, 1603-1621.

Beroza, G. C. and P. Spudich, 1988: Linearized inversion for fault rupture behavior: Application to the 1984 Morgan Hill, California, earthquake. J. Geophys. Res., 93, 
6275-6296, doi: 10.1029/JB093iB06p06275. [Link]

Bos, A. G., W. Spakman, and M. C. J. Nyst, 2003: Surface deformation and tectonic setting of Taiwan inferred from a GPS velocity field. J. Geophys. Res., 108, doi: 10.1029/2002JB002336. [Link]

Chan, C. H. and Y. M. Wu, 2012: A seismicity burst following the 2010 M6.4 Jiashian earthquake - implications for short-term seismic hazards in southern Taiwan. J. Asian Earth Sci., 59, 231-239, doi: 10.1016/j. jseaes.2012.08.011. [Link]

Chen, C. H., W. H. Wang, and T. L. Teng, 2003: A Possible causal relationship between the 1998 Ruey-Li Sequence and the 1999 Chi-Chi earthquake in Taiwan. Bull. Seismol. Soc. Am., 93, 1542-1558, doi: 10.1785/0120020174. [Link]

Chiang, C. S., H. S. Yu, and Y. W. Chou, 2004: Characteristics of the wedge-top depozone of the southern Taiwan foreland basin system. Basin Res., 16, 65-78, doi: 10.1111/j.1365-2117.2004.00222.x. [Link]

Chiang, P. H., Y. J. Hsu, and W. L. Chang, 2016: Fault modeling of the 2012 Wutai, Taiwan earthquake and its tectonic implications. Tectonophysics, 666, 66-75, doi: 10.1016/j.tecto.2015.10.015. [Link]

Ching, K. E., K. M. Johnson, R. J. Rau, R. Y. Chuang, L. C. Kuo, and P. L. Leu, 2011: Inferred fault geometry and slip distribution of the 2010 Jiashian, Taiwan, earthquake is consistent with a thick-skinned deformation model. Earth Planet. Sci. Lett., 301, 78-86, doi: 10.1016/j.eps1.2010.10.021. [Link]

Cohee, B. P. and G. C. Beroza, 1994: Slip distribution of the 1992 Landers earthquake and its implications for earthquake source mechanics. Bull. Seismol. Soc. Am., 84, 692-712.

Hartzell, S. H. and T. H. Heaton, 1983: Inversion of strong ground motion and teleseismic waveform data for the fault rupture history of the 1979 Imperial Valley, California, earthquake. Bull. Seismol. Soc. Am., 73, 1553-1583.

Hsieh, S. H., 1970: Geology and gravity anomalies of the Pingtung Plain, Taiwan. Proc. Geol. Soc. China, 13, 76-89.

Huang, S. T., K. M. Yang, J. H. Hung, J. C. Wu, H. H. Ting, W. W. Mei, S. H. Hsu, and M. Lee, 2004: Deformation front development at the northeast margin of the Tainan basin, Tainan-Kaohsiung area, Taiwan. Mar. Geophys. Res., 25, 139-156, doi: 10.1007/s11001-0050739-z. [Link]

Huang, H. H., Y. M. Wu, T. L. Lin, W. A. Chao, J. B. H. Shyu, C. H. Chan, and C. H. Chang, 2011: The preliminary study of the 4 March $2010 \mathrm{Mw} 6.3$ Jiasian, Taiwan earthquake sequence.Terr. Atmos. Ocean.Sci., 22, 283-290, doi: 10.3319/TAO.2010.12.13.01(T). [Link]

Lacombe, O. and F. Mouthereau, 2002: Basement-involved shortening and deep detachment tectonics in fore- lands of orogens: Insights from recent collision belts (Taiwan, western Alps, Pyrenees). Tectonics, 21, doi: 10.1029/2001TC901018. [Link]

Lacombe, O., F. Mouthereau, J. Angelier, and B. Deffontaines, 2001: Structural, geodetic and seismological evidence for tectonic escape in SW Taiwan. Tectophysics, 333, 323-345, doi: 10.1016/S0040-1951(00)00281X. [Link]

Lee, S. J., L. Mozziconacci, W. T. Liang, Y. J. Hsu, W. G. Huang, and B. S. Huang, 2013: Source complexity of the 4 March 2010 Jiashian, Taiwan, earthquake determined by joint inversion of teleseismic and near field data. J. Asian Earth Sci., 64, 14-26, doi: 10.1016/j.jseaes.2012.11.018. [Link]

Lee, T. Y., C. H. Tang, J. S. Ting, and J. Y. Y.Hsu, 1993: Sequence stratigraphy of the Tainan basin, offshore southwestern Taiwan. Petrol. Geol. Taiwan, 28, 119-158.

Leggett, J. K., W. S. McKerrow, and M. H. Eales, 1979: The Southern Uplands of Scotland: A Lower Palaeozoic accretionary prism. J. Geol. Soc., 136, 755-770, doi: 10.1144/gsjgs.136.6.0755. [Link]

Lin, A. T. and A. B. Watts, 2002: Origin of the west Taiwan basin by orogenic loading and flexure of a rifted continental margin. J. Geophys. Res., 107, doi: 10.1029/2001JB000669. [Link]

Lin, A. T., B. Yao, S. K. Hsu, C. S. Liu, and C. Y. Huang, 2009: Tectonic features of the incipient arc-continent collision zone of Taiwan: Implications for seismicity. Tectonophysics, 479, 28-42, doi: 10.1016/j.tecto.2008.11.004. [Link]

Lin, C. W., H. C. Chang, S. T. Lu, T. S Shih, and W. J. Huang, 2000: An introduction to the active faults of Taiwan $\left(2^{\text {nd }}\right.$ Ed.). Central Geological Survey, MOEA, Taiwan.

Michael, A. J., 1987: Use of focal mechanisms to determine stress: A control study. J. Geophys. Res., 92, 357-368, doi: 10.1029/JB092iB01p00357. [Link]

Nur, A., H. Ron, and O. Scotti, 1986: Fault mechanics and the kinematics of block rotations. Geology, 14, 746749, doi: 10.1130/0091-7613(1986)14<746:FMAT$\mathrm{KO}>2.0 . \mathrm{CO} ; 2$. [Link]

Olson, A. H. and R. J. Apsel, 1982: Finite faults and inverse theory with applications to the 1979 Imperial Valley earthquake. Bull. Seismol. Soc. Am., 72, 1969-2001.

Papageorgiou, A. S. and K. Aki, 1983a: A specific barrier model for the quantitative description of inhomogeneous faulting and the prediction of strong ground motion. I. Description of the model. Bull. Seismol. Soc. Am., 73, 693-722.

Papageorgiou, A. S. and K. Aki, 1983b: A specific barrier model for the quantitative description of inhomogeneous faulting and the prediction of strong ground motion. Part II. Applications of the model. Bull. Seismol. Soc. Am., 73, 953-978. 
Rau, R. J. and F. T. Wu, 1998: Active Tectonics of Taiwan Orogeny From Focal Mechanisms of Small-to-moderate-size Earthquakes. Terr. Atmos. Ocean. Sci., 9, 755778, doi: 10.3319/TAO.1998.9.4.755(TAICRUST). [Link]

Reasenberg, P. and D. Oppenheimer, 1985: Fpfit, fpplot, and fppage: Fortran computer programs for calculating and displaying earthquake fault-plane solutions. OpenFile Report, No.85-739, U. S. Geological Survey.

Robinson, R. and P. J. McGinty, 2000: The enigma of the Arthur's Pass, New Zealand, earthquake: 2. The aftershock distribution and its relation to regional and induced stress fields. J. Geophys. Res., 105, 1613916150, doi: 10.1029/2000JB900012. [Link]

Shyu, J. B. H., K. Sieh, Y. G. Chen, and C. S. Liu, 2005: Neotectonic architecture of Taiwan and its implications for future large earthquakes. J. Geophys. Res., 110, B08402, doi: 10.1029/2004JB003251. [Link]

Sibuet, J. C., S. K. Hsu, and E. Debayle, 2004: Geodynamic context of the Taiwan orogeny. In: Clift, P., W. Kuhnt, P. Wang, and D. Hayes (Eds.), Continent-Ocean Interactions Within East Asian Marginal Seas, American Geophysical Union, Washington, D.C., 127-158, doi: 10.1029/149GM08. [Link]

Spudich, P. and L. N. Frazer, 1984: Use of ray theory to calculate high-frequency radiation from earthquake sources having spatially variable rupture velocity and stress drop. Bull. Seismol. Soc. Am., 74, 2061-2082.

Steacy, S., J. Gomberg, and M. Cocco, 2005: Introduction to special section: Stress transfer, earthquake triggering, and time-dependent seismic hazard. J. Geophys. Res., 110, B05S01, doi: 10.1029/2005JB003692. [Link]

Suppe, J., 1981: Mechanics of mountain building and metamorphism in Taiwan. Mem. Geol. Soc. China, 4, 67-89.

Takeo, M., 1987: An inversion method to analyze the rupture processes of earthquakes using near-field seismograms. Bull. Seismol. Soc. Am., 77, 490-513.
Thurber, C. H., 1983: Earthquake locations and three-dimensional crustal structure in the Coyote lake area, central California. J. Geophys. Res., 88, 8226-8236, doi: 10.1029/JB088iB10p08226. [Link]

Trifunac, M. D., 1974: A three-dimensional dislocation model for the San Fernando, California, earthquake of February 9, 1971. Bull. Seismol. Soc. Am., 64, 149-172.

Tsan, S. F. and W. P. Keng, 1968: The Neogene rocks and major structural features of southwestern Taiwan. Proc. Geol. Soc. China, 11, 45-59.

Wald, D. J., D. V. Helmberger, and T. H. Heaton, 1991: Rupture model of the 1989 Loma Prieta earthquake from the inversion of strong motion and broadband teleseismic data. Bull. Seismol. Soc. Am., 81, 1540-1572.

Wen, S., C. H. Chen, and T. L. Teng, 2008: Ruptures in a highly fractured upper crust. Pure Appl. Geophys., 165, 201-213, doi: 10.1007/s00024-008-0297-9. [Link]

Wen, S., H. J. Hsu, W. Y. Chang, and C. H. Chen, 2012: A study of the seismogenic process beneath the southwestern foothills in Taiwan in relation with the 2010 Jiasian earthquake. Tectonophysics, 570-571, 57-64, doi: 10.1016/j.tecto.2012.06.029. [Link]

Wu, Y. M., C. H. Chang, L. Zhao, J. B. H. Shyu, Y. G. Chen, K. Sieh, and J. P. Avouac, 2007: Seismic tomography of Taiwan: Improved constraints from a dense network of strong motion stations. J. Geophys. Res., 112, B08312, doi: 10.1029/2007JB004983. [Link]

Yu, S. B., Y. T. Yeh, and Y. B. Tsai, 1983: Microearthquake activity in southwestern Taiwan. Bull. Inst. Earth Sci., Academica Sinica, 3, 71-85.

Yu, S. B.,H. Y. Chen, and L. C. Kuo, 1997: Velocity field of GPS stations in the Taiwan area. Tectonophysics, 274, 41-59, doi: 10.1016/s0040-1951(96)00297-1. [Link]

Zeng, Y., K. Aki, and T. L. Teng, 1993: Mapping of the high-frequency source radiation for the Loma Prieta earthquake, California. J. Geophys. Res., 98, 1198111993, doi: 10.1029/93JB00346. [Link] 